\title{
Coverage Effects of the ACA's Medicaid Expansion on Adult Reproductive-Aged Women, Postpartum Mothers, and Mothers with Older Children
}

\author{
Lindsey Rose Bullinger ${ }^{1}$ (I) $\cdot$ Kosali Simon ${ }^{2} \cdot$ Brownsyne Tucker Edmonds $^{3}$ \\ Accepted: 12 February 2022 / Published online: 6 March 2022 \\ (c) The Author(s), under exclusive licence to Springer Science+Business Media, LLC, part of Springer Nature 2022
}

\begin{abstract}
Objectives We estimate the effect of the Affordable Care Act's (ACA) Medicaid expansions on Medicaid coverage of reproductive-aged women at varying childbearing stages.

Methods Using data from the American Community Survey (ACS) $(n=1,977,098)$ and a difference-in-differences approach, we compare Medicaid coverage among low-income adult women without children, postpartum mothers, and mothers of children older than one year in expansion states to non-expansion states, before and after the expansions.

Results The ACA's Medicaid expansion increased Medicaid coverage among adult women with incomes between 101 and $200 \%$ of the federal poverty line (FPL) without children by 10.7 percentage points ( 54 percent, $p<0.01$ ). Coverage of mothers with children older than one year increased by 9.5 percentage points $(34$ percent, $p<0.01$ ). Coverage of mothers with infants rose by 7.9 percentage points $(21$ percent, $\mathrm{p}<0.01)$.

Conclusions for Practice Within the population of adult reproductive-aged women, we find a "fanning out" of effects from the ACA's Medicaid expansions. Childless women experience the largest gains in coverage while mothers of infants experience the smallest gains; mothers of children greater than one year old fall in the middle. These results are consistent with ACA gains being the smallest among the groups least targeted by the ACA, but also show substantial gains (one fifth) even among postpartum mothers.
\end{abstract}

Keywords Health insurance $\cdot$ Medicaid · Affordable Care Act · Women's health · Postpartum health

\section{Significance}

"What is already known on this subject?"

Research has shown that the Affordable Care Act's Medicaid expansions have reduced uninsurance among women of reproductive age, but there may be variation in coverage effects even within this population.

"What this study adds?"

Lindsey Rose Bullinger

lrbullin@gatech.edu

1 School of Public Policy, Georgia Tech, 685 Cherry St., Atlanta, GA 30332, USA

2 O'Neill School of Public and Environmental Affairs, Indiana University, 1315 East Tenth Street, Bloomington, IN 47405, USA

3 Department of Obstetrics and Gynecology, Indiana University School of Medicine, 550 University Blvd., University Hospital 2440, Indianapolis, IN 46202, USA
Using nationally representative data, we compare Medicaid coverage among childless women, postpartum mothers, and mothers of children older than one year in expansion states to nonexpansion states. We find variation in impacts within the population of reproductive-aged women. Childless women experience the largest gains in Medicaid coverage while postpartum mothers experience the smallest gains; mothers of children greater than one year old are in the middle.

\section{Introduction}

For women of reproductive age, health insurance can be vital for providing access to healthcare services benefitting both mothers and children. In addition to health insurance generally supporting better health for women-a significant goal itself-insurance coverage of women of reproductive age also has important implications for children's health. 
For example, access to medical care for pregnant women improves child health by increasing prenatal care, lowering the incidence of infant mortality, and improving birth outcomes (Currie \& Gruber, 1996).

Health insurance coverage for nonpregnant women before (pre-conceptional period) and after pregnancy (interconceptional period) also has significant potential to improve the health of future children in a variety of ways (Johnson et al., 2006). First, insurance coverage can prevent health shocks, manage chronic diseases, and support overall preconception health which is associated with maternal and infant health outcomes (Stephenson et al., 2018). Second, access to contraceptives reduces unplanned pregnancies (Kearney \& Levine, 2009), which can increase parental investments in children (Bailey, 2013). Finally, after childbirth, health insurance coverage can increase women's access to pregnancy-related healthcare, including physical recovery and postpartum mental health, which are also predictors of child health and well-being (Case \& Paxson, 2002; Dietz et al., 2009).

Beginning in the 1980s, pregnant women with incomes less than 133 percent FPL were categorically eligible for Medicaid. Since then, many states have expanded the income threshold, with some exceeding 200 percent FPL. As a result, Medicaid coverage during pregnancy is relatively high. But standard Medicaid pregnancy coverage is temporary, often limited to 60 days following childbirth. ${ }^{1}$ Many mothers then become uninsured after their pregnancyrelated Medicaid is terminated. For example, between 2005 and 2013, more than half of women who were covered by Medicaid at the time of delivery became uninsured during the next six months (Daw et al., 2017). Health insurance coverage before and between pregnancy may be even more important for low-income women, who are more likely to experience health problems regardless of pregnancy status.

The ACA's Medicaid expansions, which increased Medicaid eligibility to low-income adults (under 138\% FPL), have increased insurance coverage for low-income women (Courtemanche et al., 2017; Johnston et al., 2018; Simon et al., 2017; Wehby \& Lyu, 2018). Though these increases have been driven by women without dependent children (Johnston et al., 2018; Simon et al., 2017), parents also experienced increased coverage (McMorrow et al., 2017).

Previous research has shown that the ACA broadly (Daw \& Sommers, 2019) and Medicaid expansions specifically (Johnston et al., 2018) have reduced uninsurance among

\footnotetext{
${ }^{1}$ In more recent policy than covered by our study period-starting in April 2022 - states will have an option to amend their state plans to extend post-partum coverage to 60 months under the American Rescue Plan of 2021 (https://www.congress.gov/bill/117th-congress/ house-bill/1319/).
}

women of reproductive age. Descriptive analyses also suggest that uninsurance among new mothers (McMorrow $\&$ Kenney, 2018) and insurance disruptions (i.e., churn) between preconception and postpartum (Daw et al., 2019) are both lower in expansion states than non-expansion states. Other research has shown increases in insurance coverage among new mothers and preconception coverage (Adams et al., 2019; Clapp et al.,; 2018; Daw et al., 2020; Geiger et al., 2021; Lyu \& Wehby, 2021). Primarily due to the categorical eligibility of pregnant women and postpartum mothers up to 60 days, we expect there are differences even within the population of reproductive-aged women.

Our research builds upon this prior research and makes important contributions. First, like Daw and Sommers (2019), Johnston et al. (2018), and Lyu and Wehby (2021) we study all reproductive-aged women. Second, as in Johnston et al. (2018), McMorrow and Kenney (2018), Daw et al. (2019), Clapp et al. (2018), Adams et al. (2019), Daw et al. (2020), Lyu and Wehby (2021), and Geiger et al. (2021) we examine Medicaid expansions specifically. We extend McMorrow and Kenney (2018) and Daw et al. (2019) by rigorously analyzing the causal impact of the expansions. Further, we also extend Johnston et al. (2018) by estimating the effects on Medicaid coverage specifically (rather than health insurance coverage) and by examining variation in the effects of Medicaid expansions within the population of mothers by time of last pregnancy. Finally, we build upon Clapp et al. (2018), Adams et al. (2019), Daw et al. (2020), and Geiger et al. (2021) by producing a national examination of the expansions. Specifically, we use nationally representative data to estimate the effect of ACA's Medicaid expansions on Medicaid coverage of low-income reproductiveaged women, and whether there are different relative effects for women without children, women who have given birth in the past year, and women who have a child older than one year.

\section{Methods}

Using a nationally representative sample, we compared Medicaid coverage among reproductive-aged women in Medicaid expansion states to non-expansion states, before and after the expansions. We employed a difference-indifferences (DD) research design where expansion states were the treatment group and non-expansion states served as the control group. Human participant protection was not required for this study because no human participants were involved. 


\section{Data}

We used data from the American Community Survey (ACS), 2008-2017. The ACS consists of repeated cross-sections of about 3 million individuals each year. It is the largest household survey in the U.S., including about 1 percent of the entire U.S. population. This survey collects information on income, family characteristics, and socioeconomic and demographic data. All 50 states and Washington, D.C. were included in our analysis. We limited the sample to adult women of reproductive age (18-44) with incomes less than $200 \%$ of the federal poverty line (FPL) since the expansions extended coverage to adults.

The outcome of interest was Medicaid coverage, a binary variable indicating that the respondent was covered by Medicaid. We defined Medicaid expansion as states that expanded as of June 2015 (expansion states are listed in Appendix A). Nearly all states that expanded their Medicaid program expanded in January 2014. We follow Simon et al. (2017) in identifying states that expanded after 2014 as expansion states only for the years in which their expansion was effective.

Some states expanded their programs before 2014. Most of these expansions were limited in some way. We followed previous literature by using a single indicator variable to measure Medicaid expansion in 2014. Nonetheless, sensitivity checks where we drop early expansion states confirmed our main results.

One of the greatest advantages of the ACS is its large sample size, which allowed us to estimate the effects of the ACA Medicaid expansions separately across adult women of reproductive age. We first separately estimated the impacts of the expansions on women without any children. This analysis adds to the literature on how the ACA affects lowincome childless adults. Next, we separated mothers into new mothers with infants (hereafter referred to as postpartum mothers) and mothers without infants. Mothers with infants were those who have given birth within the past year. Mothers without infants were those who report having a child older than one year old and did not report having a child within the past year.

Additional measures from the ACS included race/ethnicity, age, marital status, and education level. Race/ethnicity was measured as three binary variables: non-Hispanic white, non-Hispanic black, and Hispanic (reference group = Asian/ PI \& multi-racial). Age was categorized into four bins: (reference group $=18-22 ; 23-27,28-35,36-44)$. Marital status consisted of three binary variables: married, never married, and divorced (reference group = widowed). Education level was measured as three binary variables: high school graduate, some college, and bachelor's degree or more (reference group $=$ less than high school). In addition to these individual-level measures, we also adjusted for state level unemployment rates from the Bureau of Labor Statistics and state-level poverty rates from the Census Bureau which may have been associated with both whether a state expanded its Medicaid program and health insurance coverage of women. Our results were not sensitive to the inclusion of these statelevel characteristics.

\section{Statistical Analysis}

We implemented the following specification:

$Y_{i s t}=\beta_{0}+\beta_{1}$ Expansion $_{s t} *$ Post $_{t}+\gamma_{t}+\delta_{s}+\lambda^{\prime} X_{i s t}+\eta Z_{s t}+\varepsilon_{i s t}$

where $\mathrm{Y}$ is a binary variable measuring Medicaid coverage for individual $i$ in state $s$ during year $t$. Expansion was a binary variable equal to 1 if individual $i$ lived in state $s$ that expanded Medicaid during time $t$. Post equaled 1 if time $t$ is 2014 or later. States that expanded after January 2014 are only classified as expansion states in the years after the expansion was implemented in that state. The variable of interest, Expansion*Post was an interaction between these two binary variables. The parameter of interest $\beta_{1}$, represented the effect of Medicaid expansion on Medicaid coverage of women. Year fixed effects, $\gamma_{t}$, adjusted for temporal changes in health insurance coverage that occur nationwide. State fixed effects, $\delta_{s}$, adjusted for time-invariant differences across states. $X$ was a vector of individual-level covariates: race/ethnicity, age, marital status, and education level. $\mathrm{Z}$ included state-level unemployment and poverty rates, both of which may affect health insurance coverage of reproductive-aged women. Regressions were weighted by sampling weights provided in the ACS, and robust standard errors were clustered at the state-level. A key assumption of the difference-in-differences approach is that in the absence of the Medicaid expansions, Medicaid coverage among adult women of reproductive age would have remained the same across expansion and non-expansion states, and that no other factors affecting Medicaid coverage of this population occurred at the same time as Medicaid expansions. To assess whether this assumption likely holds, pre-ACA expansion trends should be similar between the two types of states. For all outcomes, the pre-expansion trends are statistically similar between expansion and non-expansion states (see Appendix B).

\section{Subgroup Analysis}

We estimated this model separately for low-income women aged 18-44 who do not have children, who had a child more than one year ago, and who had a child within the past year. We expected that women who do not have children will experience the largest impact of the ACA Medicaid expansions because Medicaid rules prior to the ACA did not afford 
many options for them to seek coverage. Very low-income women who had a child more than one year ago may have been eligible for Medicaid pre-ACA if they lived in a state where parents are eligible at higher income thresholds. Lowincome women who had a child within the past year should have been categorically eligible for at least some portion of the year (usually two months postpartum). Therefore, we expected they will experience the smallest effects from the ACA Medicaid expansions.

We also estimated the model separately for women with incomes less than 100\% FPL and for women with incomes between 101 and 200\% FPL. We expected that women with incomes between 101 and 200\% FPL were more strongly impacted by the Medicaid expansions due to the expansion to $138 \% \mathrm{FPL}$ and that pre-ACA eligibility was more common among the lowest income group.

\section{Sensitivity Analysis}

We examined the sensitivity of our results to several modifications. First, our primary models estimated an ordinary least squares (OLS) model through a linear probability model (LPM). In sensitivity analyses, we also estimated a probit model. Second, the presence of states that expanded their Medicaid programs before 2014 may have made the coverage gains appear smaller (downward bias) because these states had already increased access to public health insurance coverage earlier. In another robustness check, we omitted the states that expanded Medicaid early (California, Washington, D.C., Connecticut, Minnesota, Massachusetts, and New York).

\section{Results}

Descriptive statistics of the sample-measured by mean values-are reported in Table 1, separated by expansion and non-expansion states (across columns), both pre- and postexpansion (across panels) for each population group. Women in expansion states-regardless of childbearing status-were less likely to be non-Hispanic black and more likely to be Hispanic. Childless women in expansion states were also more highly educated. Otherwise, the demographic characteristics of women in expansion states and non-expansion states were relatively similar across childbearing status.

Before presenting the main results, Fig. 1 presents trends in Medicaid coverage among adult women of reproductive age by expansion and non-expansion states. Medicaid coverage was lowest among childless women and highest among postpartum mothers with children under age 1 . Medicaid coverage was also higher in expansion states than non-expansion states throughout the study period. Medicaid coverage increased in 2014 among women in expansion states across all three groups of women, while women in non-expansion states did not experience the same increases in coverage. Relative to the baseline coverage rates, this figure suggests the ACA Medicaid expansions had differential impacts across women of varying childbearing stages.

Table 2 presents the main results, which adjust for individual-level covariates, state-level factors, and state and year fixed effects. Panel A shows the effects for women with incomes less than 100\% FPL and Panel B displays the effects for women with incomes between 101 and 200\% FPL. Regardless of childbearing status, all low-income women experienced increases in Medicaid coverage as a result of the ACA Medicaid expansions. These results are all statistically significantly different from zero $(p<0.01)$. As expected, childless women experienced the largest increases. For example, very low-income childless women increased their Medicaid coverage by 8.0 percentage points. Relative to the baseline mean coverage in expansion states before expansion of 22.3 percent, this increase represents about a 36 percent increase. Childless women with incomes between 101 and 200 percent FPL (Panel B) saw even larger effects: 10.7 percentage points higher coverage, which represents about a 54 percent gain in Medicaid coverage.

Columns 2 and 3 separate mothers into those with children older than one and postpartum mothers with infants. Overall, mothers of older children experienced larger increases in Medicaid coverage relative to postpartum mothers, and this difference is consistent across the two income groups. Specifically, very low-income mothers with older children (Panel A) — who would not have been categorically eligible for Medicaid in the past year-increased their Medicaid coverage by 6.8 percentage points, or 12.3 percent. Postpartum mothers of infants-who would have been eligible for pregnancy and/or postpartum coverage for part of the year-experienced smaller increases of 4.4 percentage points, or about 7 percent.

Moving to Panel B, the ACA Medicaid expansions had larger effects on women with incomes between 101 and $200 \%$ FPL than women with incomes less than $100 \%$ FPL. Since pre-ACA eligibility was more likely among the lowest income women, this finding is not surprising. In particular, Medicaid coverage among mothers of older children in this income group rose by 9.5 percentage points, or roughly 34 percent. Postpartum mothers in this income group increased their Medicaid coverage by 7.9 percentage points (21 percent).

These results are not sensitive to model specification. In Appendix $\mathrm{C}$, we report marginal effects from a probit model, and found the magnitudes are similar to the main results. For example, results remain largest among childless women with incomes between 101 and 200\% FPL and smallest among mothers with infants. Probit models estimate an increase in Medicaid coverage among childless women of between 26 
Table 1 Descriptive statistics of adult women of reproductive age, before and after ACA medicaid expansions

\begin{tabular}{|c|c|c|c|c|c|c|}
\hline & \multicolumn{2}{|c|}{ Childless Women } & \multicolumn{2}{|c|}{ Mothers with Children $>1$} & \multicolumn{2}{|c|}{ Postpartum Mothers } \\
\hline & Expansion & $\begin{array}{l}\text { Non- } \\
\text { Expansion }\end{array}$ & Expansion & $\begin{array}{l}\text { Non- } \\
\text { Expansion }\end{array}$ & Expansion & $\begin{array}{l}\text { Non- } \\
\text { Expansion }\end{array}$ \\
\hline \multicolumn{7}{|l|}{ Panel A: Pre-2014 } \\
\hline \multicolumn{7}{|l|}{ Outcome } \\
\hline Covered by Medicaid & 0.213 & 0.162 & 0.410 & 0.255 & 0.513 & 0.358 \\
\hline \multicolumn{7}{|c|}{ Individual-level Covariates } \\
\hline Non-Hispanic White & 0.655 & 0.664 & 0.614 & 0.624 & 0.604 & 0.622 \\
\hline Non-Hispanic Black & 0.133 & 0.226 & 0.158 & 0.260 & 0.159 & 0.252 \\
\hline Hispanic & 0.217 & 0.159 & 0.355 & 0.252 & 0.351 & 0.262 \\
\hline Age $18-22$ & 0.500 & 0.505 & 0.056 & 0.061 & 0.248 & 0.283 \\
\hline Age $23-27$ & 0.220 & 0.210 & 0.155 & 0.167 & 0.304 & 0.319 \\
\hline Age $28-35$ & 0.150 & 0.144 & 0.369 & 0.373 & 0.333 & 0.304 \\
\hline Age $36-44$ & 0.130 & 0.141 & 0.421 & 0.399 & 0.114 & 0.094 \\
\hline Married & 0.087 & 0.098 & 0.432 & 0.424 & 0.433 & 0.429 \\
\hline Never Married & 0.836 & 0.801 & 0.352 & 0.327 & 0.476 & 0.467 \\
\hline Divorced & 0.053 & 0.069 & 0.138 & 0.154 & 0.055 & 0.058 \\
\hline High School Graduate & 0.371 & 0.398 & 0.419 & 0.436 & 0.441 & 0.448 \\
\hline Some College & 0.358 & 0.346 & 0.267 & 0.276 & 0.242 & 0.247 \\
\hline Bachelor's + & 0.146 & 0.119 & 0.083 & 0.081 & 0.083 & 0.081 \\
\hline \multicolumn{7}{|l|}{ State-level Covariates } \\
\hline Unemployment Rate & 8.651 & 7.803 & 8.757 & 7.831 & 8.689 & 7.756 \\
\hline Poverty Rate & 14.190 & 15.321 & 14.363 & 15.594 & 14.271 & 15.481 \\
\hline No. of Observations & 300,979 & 250,575 & 272,429 & 259,063 & 50,789 & 48,302 \\
\hline \multicolumn{7}{|l|}{ Panel B: Post-2014 } \\
\hline \multicolumn{7}{|l|}{ Outcome } \\
\hline Covered by Medicaid & 0.331 & 0.180 & 0.534 & 0.283 & 0.621 & 0.394 \\
\hline \multicolumn{7}{|c|}{ Individual-level Covariates } \\
\hline Non-Hispanic White & 0.639 & 0.646 & 0.601 & 0.618 & 0.600 & 0.618 \\
\hline Non-Hispanic Black & 0.135 & 0.239 & 0.164 & 0.265 & 0.170 & 0.259 \\
\hline Hispanic & 0.223 & 0.188 & 0.350 & 0.292 & 0.323 & 0.280 \\
\hline Age $18-22$ & 0.481 & 0.475 & 0.043 & 0.047 & 0.187 & 0.218 \\
\hline Age $23-27$ & 0.236 & 0.230 & 0.149 & 0.154 & 0.307 & 0.317 \\
\hline Age $28-35$ & 0.163 & 0.161 & 0.378 & 0.381 & 0.377 & 0.351 \\
\hline Age $36-44$ & 0.120 & 0.133 & 0.430 & 0.418 & 0.130 & 0.115 \\
\hline Married & 0.080 & 0.096 & 0.413 & 0.413 & 0.429 & 0.424 \\
\hline Never Married & 0.854 & 0.815 & 0.391 & 0.358 & 0.486 & 0.474 \\
\hline Divorced & 0.047 & 0.059 & 0.127 & 0.142 & 0.052 & 0.061 \\
\hline High School Graduate & 0.382 & 0.403 & 0.423 & 0.421 & 0.450 & 0.455 \\
\hline Some College & 0.358 & 0.350 & 0.280 & 0.292 & 0.262 & 0.265 \\
\hline Bachelor's + & 0.159 & 0.129 & 0.096 & 0.097 & 0.107 & 0.102 \\
\hline \multicolumn{7}{|l|}{ State-level Covariates } \\
\hline Unemployment Rate & 5.338 & 5.057 & 5.398 & 5.087 & 5.360 & 5.025 \\
\hline Poverty Rate & 12.872 & 14.467 & 13.057 & 14.632 & 12.982 & 14.481 \\
\hline No. of Observations & 248,698 & 163,778 & 180,642 & 142,578 & 33,226 & 26,039 \\
\hline
\end{tabular}

Source: American Community Survey, 2008-2017. Sample is restricted to adult reproductive-aged women (aged 18-44) with incomes less than 200\% FPL. Mean values across (1) expansion and non-expansion states (according to Appendix A) and (2) pre- and post-2014 are shown for each population group 
Fig. 1 Medicaid coverage among adult women of reproductive age $(18-44)<=200$ FPL. Source: American Community Survey, 2008-2017
Medicaid Coverage Among Adult Women of Reproductive Age (18-44) $<=200$ FPL
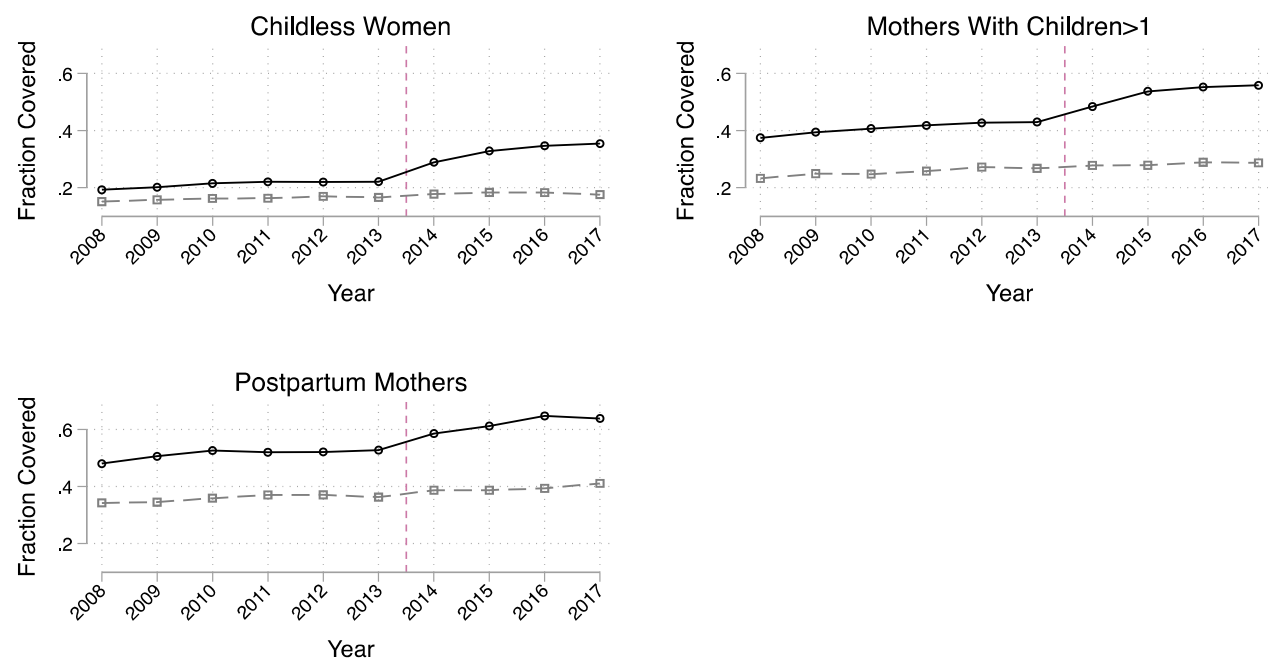

$\rightarrow$ Expansion States
$\rightarrow-\quad$ Non-Expansion States

that early expansion states are not biasing the main estimates downward. In sum, our sensitivity analyses indicate that the results are not driven by our analytical decisions.

\section{Discussion}

In this study using nationally representative data on Medicaid coverage among reproductive-aged women at varying childbearing stages, we found significant increases in

Table 2 Effect of medicaid expansion on medicaid coverage of adult women of reproductive age

Medicaid Coverage Among Adult Women of Reproductive Age (18-44)

Childless Women $\quad$ Mothers with Chil- $\quad$ Postpartum Mothers dren $>1$

Panel A: Women with Incomes $<100$ FPL

Expansion*Post

$0.080 * *$

$(0.010)$

Mean Fraction Covered by Medicaid in Expansion States Pre-2014

Relative \% Change

N

Panel B: Women With Incomes 101-200 FPL

Expansion*Post

Mean Fraction Covered by Medicaid in Expansion States Pre-2014

Relative \% Change

$\mathrm{N}$
0.223

$35.9 \%$

611,619

$0.107 * *$

(0.011)

0.197

$54.2 \%$

352,411
$0.068 * *$

(0.014)

0.551

$12.3 \%$

394,604

$0.095^{* *}$

(0.014)

0.281

$33.8 \%$

460,108
$0.044^{* *}$

(0.015)

0.622

$7.1 \%$

86,463

$0.079 * *$

(0.017)

0.374

$21.1 \%$

71,893

Source: American Community Survey 2008-2017. Sample is restricted to adult reproductive-aged women (18-44). Notes: Regressions adjust for race/ethnicity, age, marital status, education, state unemployment rate, state poverty rate, state fixed effects, and year fixed effects. Regressions weighted by person weights. Robust SEs clustered at the state level. $* \mathrm{p}<0.05$, $* * \mathrm{p}<0.01$ 
Medicaid coverage as a result of the ACA Medicaid expansions. Importantly, these results confirm that there is variation in the impacts of the ACA Medicaid expansions by childbearing status among the population of adult women of reproductive age, and even among the population of lowincome mothers. Specifically, childless women experienced the largest gains in coverage while postpartum mothers experience the smallest gains; mothers of children greater than one year old are in the middle.

This "fanning out" of effects from childless women to mothers giving birth within the past year is consistent with what we would expect. Since childless women were generally not eligible for public health insurance pre-ACA, they were expected to display the largest effects. Some parents were eligible for Medicaid pre-ACA, though variation in eligibility was largely state-specific. Postpartum women were expected to benefit the least from the ACA expansions, as they had more consistent eligibility before the ACA expansions. Nonetheless, postpartum mothers still experienced large increases in Medicaid coverage.

Increased health insurance coverage during the preconceptional and interconceptional periods for low-income women may have implications for maternal and child health outcomes. For example, increased access to family planning services and regular access to preconception healthcare are predictors of timely prenatal care (Wally et al., 2018) which is associated with improved infant health (CDC, 2000). In the postpartum period, access to care for the diagnosis of both physical and mental health conditions in the postpartum period may also improve both maternal and child health outcomes. For mothers, access to postpartum are may be vitally important for maternal mortality, particularly when the maternal mortality rate in the U.S. is rising and is higher than in any other developed country (Report from Nine Maternal Mortality Review Committees, 2018). Although coverage from pregnancy-related Medicaid typically lasts up to 60 days postpartum, a recent report from maternal mortality review boards found that 20 percent of pregnancy-related deaths occurred after 43 days postpartum (Report from Nine Maternal Mortality Review Committees, 2018) suggesting that extending coverage beyond two months postpartum through the 2021 American Recovery Act in 2022, as well as the across-the-board suspension of Medicaid disenrollment during the U.S. Public Health Emergency ${ }^{2}$ could potentially save the lives of some new mothers.

The primary limitation of this study is the 4-year postexpansion period we examine. Particularly in light of recent

\footnotetext{
2 Through the March 2020 "Families First Coronavirus Response Act" states were required to provide continuous eligibility for Medicaid enrollees until the end of the Public Health Emergency (PHE). As of this writing, the PHE has not ended.
}

increases in uninsurance rates (Sommers et al., 2018) the trends we detect may not continue on their implied trajectory. Indeed, this trend can be seen in Fig. 1 where Medicaid coverage begins to flatten or even drop in 2017. A second limitation is that the ACS is self-reported data. Standard issues with self-reporting such as recall bias, social desirability bias, or reporting Medicaid coverage incorrectly are present. Finally, our results are plausibly causal effects as long as trends in reproductive-aged women's Medicaid coverage did not influence the decision to expand Medicaid. The decision to expand Medicaid was largely a political one (Jacobs \& Callaghan, 2013), and is therefore unlikely to be a response to women's health insurance coverage.

Although previous research has found that the ACA's Medicaid expansions improved health insurance coverage among reproductive-aged women (Johnston et al., 2018) our results show that even within this population there is variation in impacts based on childbearing status and time since childbirth. Specifically, postpartum mothers (who are typically eligible for two months of postpartum care even pre-ACA) were affected less by the expansions than mothers of children older than one year old. By expanding Medicaid to low-income adults, the ACA's Medicaid expansions may have also reduced insurance churn among reproductiveaged women during preconception periods, which is associated with disruptions in physician care, greater emergency department use, and worse health outcomes (Sommers et al., 2016).

The findings of this study have implications beyond the ACA. Expanding Medicaid programs to cover nonpregnant women during pre-conceptional and interconceptional periods can increase health insurance coverage among reproductive-aged women. Indeed, legislation extending postpartum coverage has been proposed at the federal level. The Mothers and Offspring Mortality and Morbidity Awareness (MOMMA) Act and the Maximizing Outcomes for Moms through Medicaid Improvement and Enhancement of Services (MOMMIES) Act would both extend Medicaid coverage for pregnant women from its current 60 days to one year. More recently, the American Rescue Plan Act of 2021 allows states to extend Medicaid postpartum coverage from 60 days to 12 months by filing a State Plan Amendment to their Medicaid programs, rather than using a Sect. 1115 demonstration waiver as was previously required. This change in federal policy should make it easier for states to expand their postpartum coverage. Though these proposals and legislation are promising for reducing postpartum uninsurance, our results suggest there is demand for health insurance coverage among women beyond the perinatal period that could be important for maternal and child health. While postpartum expansions may be a helpful first step in enhancing surveillance for postpartum complications and access to care for pregnancy-related illnesses, broader expansions that do not 
rely on categorical pregnancy eligibility, such as the ACA's Medicaid expansions, are likely more impactful for increasing continuous insurance coverage among reproductive-aged women to preemptively enhance women's access to healthcare services (in advance of and between pregnancies).

\section{Medicaid Expansion States}

\begin{tabular}{|c|c|c|}
\hline & Expansion States & Non-expansion States \\
\hline 1 & Alaska & Alabama \\
\hline 2 & Arizona & Florida \\
\hline 3 & Arkansas & Georgia \\
\hline 4 & California & Idaho \\
\hline 5 & Colorado & Kansas \\
\hline 6 & Connecticut & Maine \\
\hline 7 & Delaware & Mississippi \\
\hline 8 & District of Columbia & Missouri \\
\hline 9 & Hawaii & Nebraska \\
\hline 10 & Illinois & North Carolina \\
\hline 11 & Indiana & Oklahoma \\
\hline 12 & Iowa & South Carolina \\
\hline 13 & Kentucky & South Dakota \\
\hline 14 & Louisiana & Tennessee \\
\hline 15 & Maryland & Texas \\
\hline 16 & Massachusetts & Utah \\
\hline 17 & Michigan & Virginia \\
\hline 18 & Minnesota & Wyoming \\
\hline 19 & Montana & \\
\hline 20 & Nevada & \\
\hline 21 & New Hampshire & \\
\hline 22 & New Jersey & \\
\hline 23 & New Mexico & \\
\hline 24 & New York & \\
\hline 25 & North Dakota & \\
\hline 26 & Ohio & \\
\hline 27 & Oregon & \\
\hline 28 & Pennsylvania & \\
\hline 29 & Rhode Island & \\
\hline 30 & Vermont & \\
\hline 31 & Washington & \\
\hline 32 & West Virginia & \\
\hline 33 & Wisconsin & \\
\hline
\end{tabular}

Notes: We follow Simon et al. (2017) in categorizing expansion and non-expansion states. In particular, the Medicaid expansion became effective in January 2014 for all expansion states except for Alaska (September 2015), Indiana (February 2015), Louisiana (July 2016), Michigan (April 2014), Montana (January 2016), New Hampshire (August 2014), and Pennsylvania (January 2015). States that expanded after January 2014 are only classified as expansion states in the years after the expansion was implemented in that state. Although Wisconsin did not technically expand its Medicaid program under the ACA, it covers adults up to $100 \%$ FPL. Other states have since adopted expansions, however their effective dates are beyond the time period in this study: Idaho (2019), Maine (2019), Nebraska (2019), Utah (2019), and Virginia (2019).

\section{Pre-expansion Linear Trends Tests}

\begin{tabular}{|c|c|c|c|}
\hline & \multicolumn{3}{|c|}{$\begin{array}{l}\text { Medicaid coverage among adult women of } \\
\text { reproductive age (18-44) }\end{array}$} \\
\hline & $\begin{array}{l}\text { Childless } \\
\text { Women }\end{array}$ & $\begin{array}{l}\text { Mothers } \\
\text { with Chil- } \\
\text { dren }>1\end{array}$ & $\begin{array}{l}\text { New Mothers } \\
\text { with Chil- } \\
\text { dren }<1\end{array}$ \\
\hline \multicolumn{4}{|l|}{$\begin{array}{l}\text { Panel A: } \\
\text { Women with } \\
\text { Incomes }<100 \\
\text { FPL }\end{array}$} \\
\hline Expansion*Year & $\begin{array}{l}0.002 \\
(0.002)\end{array}$ & $\begin{array}{l}0.003 \\
(0.003)\end{array}$ & $\begin{array}{l}0.001 \\
(0.004)\end{array}$ \\
\hline $\mathrm{N}$ & 343859 & 246933 & 54468 \\
\hline \multicolumn{4}{|c|}{$\begin{array}{l}\text { Panel B: Women With Incomes } \\
\text { 101-200 FPL }\end{array}$} \\
\hline Expansion*Year & $\begin{array}{l}0.003 \\
(0.001)\end{array}$ & $\begin{array}{l}0.003 \\
(0.002)\end{array}$ & $\begin{array}{l}0.003 \\
(0.004)\end{array}$ \\
\hline $\mathrm{N}$ & 207695 & 284559 & 44623 \\
\hline
\end{tabular}

Source: American Community Survey 2008-2013. Sample is restricted to adult reproductive-aged women (18-44). Notes: Expansion*Year is an interaction between a binary variable representing whether a state expanded its Medicaid program and a linear year term. Regressions control for race/ ethnicity, age, marital status, education, state unemployment rate, state poverty rate, state fixed effects, and year fixed effects. Regressions weighted by person weights. Robust SEs clustered at the state level. ${ }^{*} \mathrm{p}<0.05, * * \mathrm{p}<0.01$. 


\section{Effect of Medicaid Expansion on Medicaid Coverage of Adult Women of Reproductive Age, Probit Estimates}

\begin{tabular}{|c|c|c|c|}
\hline & \multicolumn{3}{|c|}{$\begin{array}{l}\text { Medicaid coverage among adult women of repro- } \\
\text { ductive age }(18-44)\end{array}$} \\
\hline & $\begin{array}{l}\text { Childless } \\
\text { Women }\end{array}$ & $\begin{array}{l}\text { Mothers } \\
\text { with Chil- } \\
\text { dren }>1\end{array}$ & $\begin{array}{l}\text { Postpartum } \\
\text { Mothers }\end{array}$ \\
\hline \multicolumn{4}{|l|}{$\begin{array}{l}\text { Panel A: } \\
\text { Women with } \\
\text { Incomes }<100 \\
\text { FPL }\end{array}$} \\
\hline Expansion*Post & $\begin{array}{l}0.261 * * \\
(0.036)\end{array}$ & $\begin{array}{l}0.187 * * \\
(0.036)\end{array}$ & $\begin{array}{l}0.138 * * \\
(0.041)\end{array}$ \\
\hline $\begin{array}{l}\text { Mean Fraction } \\
\text { Covered by } \\
\text { Medicaid in } \\
\text { Expansion } \\
\text { States Pre- } \\
2014\end{array}$ & 0.223 & 0.551 & 0.622 \\
\hline $\mathrm{N}$ & 611619 & 394604 & 86463 \\
\hline $\begin{array}{l}\text { Panel B: } \\
\text { Women With } \\
\text { Incomes } \\
\text { 101-200 FPL }\end{array}$ & & & \\
\hline Expansion*Post & $\begin{array}{l}0.329 * * \\
(0.039)\end{array}$ & $\begin{array}{l}0.229 * * \\
(0.045)\end{array}$ & $\begin{array}{l}0.193 * * \\
(0.046)\end{array}$ \\
\hline $\begin{array}{l}\text { Mean Fraction } \\
\text { Covered by } \\
\text { Medicaid in } \\
\text { Expansion } \\
\text { States Pre- } \\
2014\end{array}$ & 0.197 & 0.281 & 0.374 \\
\hline $\mathrm{N}$ & 352411 & 460108 & 71893 \\
\hline
\end{tabular}

Source: American Community Survey 2008-2017. Sample is restricted to adult reproductive-aged women (18-44). Notes: Regressions adjust for race/ethnicity, age, marital status, education, state unemployment rate, state poverty rate, state fixed effects, and year fixed effects. Estimates are marginal effects. Regressions weighted by person weights. Robust SEs clustered at the state level. ${ }^{*} \mathrm{p}<0.05,{ }^{* *} \mathrm{p}<0.01$.
Effect of Medicaid Expansion on Medicaid Coverage of Adult Women of Reproductive Age, Excluding Early Expansion States

\begin{tabular}{|c|c|c|c|}
\hline & \multicolumn{3}{|c|}{$\begin{array}{l}\text { Medicaid coverage among adult women of repro- } \\
\text { ductive age }(18-44)\end{array}$} \\
\hline & $\begin{array}{r}\text { Childless } \\
\text { Women }\end{array}$ & $\begin{array}{l}\text { Mothers } \\
\text { with Chil- } \\
\text { dren }>1\end{array}$ & $\begin{array}{l}\text { Postpartum } \\
\text { Mothers }\end{array}$ \\
\hline \multicolumn{4}{|l|}{$\begin{array}{l}\text { Panel A: } \\
\text { Women with } \\
\text { Incomes }<100 \\
\text { FPL }\end{array}$} \\
\hline Expansion*Post & $\begin{array}{l}0.083 * * \\
(0.012)\end{array}$ & $\begin{array}{l}0.080 * * \\
(0.019)\end{array}$ & $\begin{array}{l}0.048^{*} \\
(0.020)\end{array}$ \\
\hline $\begin{array}{l}\text { Mean Fraction } \\
\text { Covered by } \\
\text { Medicaid in } \\
\text { Expansion } \\
\text { States Pre- } \\
2014\end{array}$ & 0.204 & 0.546 & 0.615 \\
\hline $\begin{array}{l}\text { Relative \% } \\
\text { Change }\end{array}$ & $40.6 \%$ & $14.7 \%$ & $7.8 \%$ \\
\hline $\mathrm{N}$ & 435228 & 295056 & 64708 \\
\hline $\begin{array}{l}\text { Panel B: } \\
\text { Women With } \\
\text { Incomes } \\
\text { 101-200 FPL }\end{array}$ & & & \\
\hline Expansion*Post & $\begin{array}{l}0.093 * * \\
(0.011)\end{array}$ & $\begin{array}{l}0.090 * * \\
(0.019)\end{array}$ & $\begin{array}{l}0.067 * * \\
(0.018)\end{array}$ \\
\hline $\begin{array}{l}\text { Mean Fraction } \\
\text { Covered by } \\
\text { Medicaid in } \\
\text { Expansion } \\
\text { States Pre- } \\
2014\end{array}$ & 0.173 & 0.262 & 0.358 \\
\hline $\begin{array}{l}\text { Relative \% } \\
\text { Change }\end{array}$ & $53.7 \%$ & $34.3 \%$ & $18.7 \%$ \\
\hline $\mathrm{N}$ & 250074 & 345046 & 53695 \\
\hline
\end{tabular}

Source: American Community Survey 2008-2017. Sample is restricted to adult reproductive-aged women (18-44), and drops early expansion states (CA, CT, DC, MA, MN, NJ, NY, WA) Notes: Regressions adjust for race/ethnicity, age, marital status, education, state unemployment rate, state poverty rate, state fixed effects, and year fixed effects. Regressions weighted by person weights. Robust SEs clustered at the state level. ${ }^{*} \mathrm{p}<0.05, * * \mathrm{p}<0.01$. 
Authors' contributions LRB conceptualized the study, developed the methodological design, curated the data, performed the formal analyses, interpreted the results, wrote the original draft, reviewed and edited the manuscript, and administered the project. KS conceptualized the study, developed the methodological design, interpreted the results, and reviewed and edited the manuscript. BTE conceptualized the study, developed the methodological design, interpreted the results, contextualized the findings, and reviewed and edited the manuscript.

Funding No funding sources.

Data Availability All data are publicly available.

Code Availability Code available upon request.

\section{Declarations}

Conflict of interest No conflicts of interest.

Ethical approval Human participant protection was not required for this study because no human participants were involved.

Consent to participate: N/A. Consent for publication: N/A.

\section{References}

Adams, E. K., Dunlop, A. L., Strahan, A. E., Joski, P., Applegate, M., $\&$ Sierra, E. (2019). Prepregnancy insurance and timely prenatal care for medicaid births: Before and after the affordable care act in Ohio. Journal of Women's Health (2002), 28(5), 654-664. https:// doi.org/10.1089/jwh.2017.6871

Bailey, M. J. (2013). Fifty years of family planning: New evidence on the long-run effects of increasing access to contraception. Brookings Papers on Economic Activity, 2013, 341-395.

Case, A., \& Paxson, C. (2002). Parental behavior and child health. Health Affairs, 21(2), 164-178. https://doi.org/10.1377/hlthaff. 21.2.164

Centers for Disease Control and Prevention (CDC). (2000). Entry into prenatal care-United States, 1989-1997. Morbidity and Mortality Weekly Report, 49(18). https://www.cdc.gov/mmWR/PDF/wk/ mm4918.pdf.

Clapp, M. A., James, K. E., Kaimal, A. J., \& Daw, J. R. (2018). Preconception coverage before and after the affordable care act medicaid expansions. Obstetrics \& Gynecology, 132(6), 1394-1400. https:// doi.org/10.1097/AOG.0000000000002972

Courtemanche, C., Marton, J., Ukert, B., Yelowitz, A., \& Zapata, D. (2017). Early impacts of the affordable care act on health insurance coverage in medicaid expansion and non-expansion states. Journal of Policy Analysis and Management, 36(1), 178-210. https://doi.org/10.1002/pam.21961

Currie, J., \& Gruber, J. (1996). Saving babies: The efficacy and cost of recent changes in the medicaid eligibility of pregnant women. Journal of Political Economy, 104(6), 1263-1296.

Daw, J. R., Kozhimannil, K. B., \& Admon, L. K. (2019). High rates of perinatal insurance churn persist after The ACA. Health Affairs Blog. https://www.healthaffairs.org/do/https://doi.org/10.1377/ hblog20190913.387157/full/.

Daw, J. R., \& Sommers, B. D. (2019). The affordable care act and access to care for reproductive-aged and pregnant women in the United States, 2010-2016. American Journal of Public Health, 109(4), 565-571. https://doi.org/10.2105/AJPH.2018.304928
Daw, J. R., Hatfield, L. A., Swartz, K., \& Sommers, B. D. (2017). Women in the United States experience high rates of coverage 'Churn' in months before and after childbirth. Health Affairs, 36(4), 598-606. https://doi.org/10.1377/hlthaff.2016.1241

Daw, J. R., Winkelman, T. N. A., Dalton, V. K., Kozhimannil, K. B., \& Admon, L. K. (2020). Medicaid expansion improved perinatal insurance continuity for low-income women. Health Affairs, 39(9), 1531-1539. https://doi.org/10.1377/hlthaff.2019.01835

Dietz, L. J., Jennings, K. D., Kelley, S. A., \& Marshal, M. (2009). Maternal depression, paternal psychopathology, and toddlers' behavior problems. Journal of Clinical Child \& Adolescent Psychology, 38(1), 48-61. https://doi.org/10.1080/153744108025753 62

Geiger, C. K., Sommers, B. D., Hawkins, S. S., \& Cohen, J. L. (2021). Medicaid expansions, preconception insurance, and unintended pregnancy among new parents. Health Services Research, 56(4), 691-701. https://doi.org/10.1111/1475-6773.13662

Jacobs, L. R., \& Callaghan, T. (2013). Why states expand medicaid: Party, resources, and history. Journal of Health Politics, Policy and Law, 38(5), 1023-1050. https://doi.org/10.1215/036168782334889

Johnson, K., Posner, S. F., Biermann, J., Cordero, J. F., Atrash, H. K., Parker, C. S., Boulet, S., \& Curtis, M. G. (2006). Recommendations to Improve Preconception Health and Health Care - United States: Report of the CDC/ATSDR Preconception Care Work Group and the Select Panel on Preconception Care. Morbidity and Mortality Weekly Report: Recommendations and Reports, 55(6), 1-CE-4. JSTOR.

Johnston, E. M., Strahan, A. E., Joski, P., Dunlop, A. L., \& Adams, E. K. (2018). Impacts of the affordable care act's medicaid expansion on women of reproductive age: Differences by parental status and state policies. Women's Health Issues, 28(2), 122-129. https://doi. org/10.1016/j.whi.2017.11.005

Kearney, M. S., \& Levine, P. B. (2009). Subsidized contraception, fertility, and sexual behavior. The Review of Economics and Statistics, 91(1), 137-151.

Lyu, W., \& Wehby, G. L. (2021). Heterogeneous effects of affordable care act medicaid expansions among women with dependent children by state-level pre-expansion eligibility. Journal of Women's Health (2002), 30(9), 1278-1287. https://doi.org/10.1089/jwh. 2020.8776

McMorrow, S., \& Kenney, G. (2018). Despite Progress Under The ACA, Many New Mothers Lack Insurance Coverage. Health Affairs Blog.

McMorrow, S., Gates, J. A., Long, S. K., \& Kenney, G. M. (2017). Medicaid expansion increased coverage, improved affordability, and reduced psychological distress for low-income parents. Health Affairs, 36(5), 808-818.

Report from Nine Maternal Mortality Review Committees (Building U.S. Capacity to Review and Prevent Maternal Deaths). (2018). Review to Action. Retrieved October 28, 2019, from https://revie wtoaction.org/Report_from_Nine_MMRCs.

Simon, K., Soni, A., \& Cawley, J. (2017). The impact of health insurance on preventive care and health behaviors: Evidence from the first two years of the ACA medicaid expansions. Journal of Policy Analysis and Management, 36(2), 390-417. https://doi.org/10. 1002/pam.21972

Sommers, B. D., Gourevitch, R., Maylone, B., Blendon, R. J., \& Epstein, A. M. (2016). Insurance churning rates for low-income adults under health reform: Lower than expected but still harmful for many. Health Affairs, 35(10), 1816-1824. https://doi.org/10. 1377/hlthaff.2016.0455

Sommers, B. D., Clark, K. L., \& Epstein, A. M. (2018). Early changes in health insurance coverage under the trump administration. New England Journal of Medicine, 378(11), 1061-1063. https://doi. org/10.1056/NEJMc1800106 
Stephenson, J., Heslehurst, N., Hall, J., Schoenaker, D. A. J. M., Hutchinson, J., Cade, J. E., Poston, L., Barrett, G., Crozier, S. R., Barker, M., Kumaran, K., Yajnik, C. S., Baird, J., \& Mishra, G. D. (2018). Before the beginning: Nutrition and lifestyle in the preconception period and its importance for future health. The Lancet, 391(10132), 1830-1841. https://doi.org/10.1016/S01406736(18)30311-8

Wally, M. K., Huber, L. R. B., Issel, L. M., \& Thompson, M. E. (2018). The association between preconception care receipt and the timeliness and adequacy of prenatal care: An examination of multistate data from pregnancy risk assessment monitoring system
(PRAMS) 2009-2011. Maternal and Child Health Journal, 22(1), 41-50. https://doi.org/10.1007/s10995-017-2352-6

Wehby, G. L., \& Lyu, W. (2018). The impact of the ACA medicaid expansions on health insurance coverage through 2015 and coverage disparities by age, race/ethnicity, and gender. Health Services Research, 53(2), 1248-1271. https://doi.org/10.1111/1475-6773. 12711

Publisher's Note Springer Nature remains neutral with regard to jurisdictional claims in published maps and institutional affiliations. 